\title{
Validity and Reliability of the Arabic Version of the Quick-Dash Questionnaire for Upper Extremity Disorders
}

\author{
AYA S.M. KHATTAB, M.Sc.*; SALWA F. ABD EL-MAJIED, Ph.D.*; NASER M. ALOTAIBI, Ph.D.** and \\ MAHA M. MOHAMMED, Ph.D.*
}

The Department of Physical Therapy for Musculoskeletal Disorders and its Surgery, Faculty of Physical Therapy, Cairo University, Egypt* and The Department of Occupational Therapy, Faculty of Allied Health Sciences, Kuwait University, Kuwait**

\begin{abstract}
Background: Upper Extremity Disorders (UEDs) are a common health problem, causing temporary and sometimes long-term work disability and implying considerable costs for employers and society. So, it is necessary to assess disability and symptoms in Egyptian patients with upper extremity disorders.

Aim of Study: To examine the reliability and validity of the Arabic Shortened Version Disabilities of the Arm, Shoulder and Hand questionnaire (Arabic Q-DASH) in UEDs.

Material and Methods: Sixty-two patients with UEDs completed the Arabic Q-DASH questionnaire at the beginning of study and after 3 days without any intervention between the baseline and second administration. Internal consistency was examined using Cronbach's alpha; test-retest reliability was measured using intra-class correlation coefficient (ICC).

Results: Cronbach's alpha of the Arabic Q-DASH questionnaire was high (Cronbach's alpha $=0.88$ ). Test-retest reliability was good (ICC: 0.84).

Conclusions: The Arabic Q-DASH questionnaire is a reliable and valid upper extremity outcome measure for assessing patients with various upper extremity disorders, whose primary language is Arabic.
\end{abstract}

Key Words: Psychometric properties - Quick-disabilities of the arm - Shoulder and hand - Reliability Validity.

\section{Introduction}

THE evidence-based medicine was developed because of a clear need to optimize the quality of patient care. It has been described as an effective set of mechanisms, not only to improve the quality

Correspondence to: Dr. Aya S.M. Khattab, The Department of Physical Therapy for Musculoskeletal Disorders and its Surgery, Faculty of Physical Therapy, Cairo University, Egypt of health care, but also to reduce medical errors caused in part by variations in clinical practice. In current medical practices, clinicians are expected to integrate clinical experience with sound use of research evidence in order to make well-informed decisions to help maximize and optimize patient well-being [1].

The need for an outcome measure which reflects the impact on function of a variety of musculoskeletal diseases and injuries in the upper extremity was independently identified by researchers from the American Academy of Orthopedic Surgeons' (AAOS) Outcomes Research [2].

The outcomes of a clinical intervention obtained by the patient i.e. patient-reported outcomes measure are seemed to be of more importance than any other outcomes like clinical, physiological or caregiver-reported. As per studies, enhanced treatment adherence and outcomes can be obtained by giving attention to patient feedback on healthcare outcomes and patient behavior change [3].

Health care professionals around the world strive to ensure the existence of valid, reliable and responsive health measurement scales. The aims are to monitor the patient's status over time, measure the improvement of the patient's condition and demonstrate the effectiveness of therapy provided. These, in turn, validate the key role of health care professionals and the validity of their services [4].

Disability of Arm, Shoulder and Hand (DASH) is a self-administered outcome measure that has been increasing in popularity since its release in 1996. Today the tool is being used around the 
world in both clinical and research settings and has proven to be a useful self-report outcome measure for people with musculoskeletal upperlimb disorders [5]. The DASH questionnaire was devised as a region specific measure by the AAOS in collaboration with a number of other organizations [2]. The rationale for use of this measure is that the upper extremity is a functional unit or kinetic chain [6].

The shortened version Disabilities of the Arm, Shoulder and Hand questionnaire (Quick-DASH) was developed as a shortened version of the DASH Outcome Measure [7]. The Q-DASH questionnaire has demonstrated good reliability, validity, and responsiveness when used for patients with UEDs [8]. Cross-cultural adaptation allows globalization of information worldwide without the loss of the conceptual meaning. This enables the exchange and comparisons of valid information among different populations worldwide [9].

The Quick-DASH questionnaire could be the preferred scale because it is easier and quicker to use [10]. Now, it has been translated into over 30 languages including English [7], Japanese [11], Swedish [8], French [10], Turkish [12], Brazilian [13], Chinese [14] and others. Despite the Arabic version of the Q-DASH being available on the official website of the Institute for Work \& Health (http://dash.iwh.on.ca/quickdash), there are no studies that have analyzed its psychometric properties. Thus, the aim of this study was to test validity and reliability of the adapted Arabic QDash questionnaire on the Egyptian population.

\section{Material and Methods}

\section{Study design:}

The study was designed as an observational validation study that was approved by the institutional review board at Faculty of Physical Therapy, Cairo University (No: P.T.REC/012/001313) from May to June 2017.

\section{Participants:}

In this study, participants were recruited from multi governmental hospitals, private centers and physical therapy services targeting upper limb conditions.

\section{A- Inclusion criteria for patients:}

All patients were chosen according to the following criteria:

- Age of at least 18 years.
- Both genders, including males and females.

- Able to read, write Arabic as a mother tongue and understand the instructions, questions in the questionnaires and forms.

- Outpatient traumatic or non-traumatic upper extremity condition, with symptoms duration of at least 4 weeks.

\section{B- Exclusion criteria for patients:}

- Infectious disease.

- Cardiac diseases or peripheral vascular disease.

- Severe cognitive or communication impairments.

- Pain in the upper limb arising from other regions (eg, the neck).

- A diagnosis of central nervous system or psychiatric disorders, and a history of tumor malignancy.

- Systemic or metabolic diseases.

\section{Data collection:}

Before data collection began, all participants read and signed an informed consent. At the baseline visit, demographic data [patient age, gender, diagnosis, arm affected, arm dominance, days since onset and mechanism of injury (traumatic versus non-traumatic)] were collected and participants completed the Arabic Quick-DASH questionnaire, a body diagram. Participants were also asked to complete the Arabic version of Quick-DASH 3 days later (the second administration with no intervention provided).

The Arabic version of shortened Disabilities of the Arm, Shoulder and Hand questionnaire:

The Arabic Quick-DASH questionnaire is an 11-item self-report questionnaire extracted from the full length version of the DASH concerning the patient's health status. Its items inquire about the degree of difficulty in performing several physical activities related to the upper extremity, the severity of pain and tingling and the problem's effect on social activities, work and sleep. The DASH has five response options for each item from $0=$ no difficulty to perform or no symptoms to $5=$ unable to do. If at least 10 out of the 11 items are completed, the responses are summed to form a raw score, and then converted to a 0-100 scale. A higher score reflects greater disability [15]. Like the DASH, it has two optional scales for work and sports that were not included in this study. 


\section{The Arabic version of DASH questionnaire:}

The DASH is a 30-item questionnaire that evaluates symptoms and physical function (at the level of disability), with a five response option for each item. Each item has five response choices that range from 1, "without any difficulty or no symptoms exist" to 5, "unable to engage in an activity or very severe symptoms". A higher score on the DASH reflects greater disability [16].

\section{Statistical analysis:}

The data sets were analyzed using the Statistical Package for Social Sciences (SPSS) version 18 software. Alpha level set at 0.05:

- Descriptive statistics including numbers, percentages, means and/or standard deviations for the demographic data for all participants were calculated in order to determine the score distributions, floor and ceiling effect.

- Cronbach's alpha coefficient and item-to-total correlation coefficients were used to examine internal consistency and reliability at the first reading.

- Item-to-total correlation coefficients were measured by Pearson correlation coefficients.

- Intra-class correlation coefficients were used to examine the test-retest reliability between the first reading and the second reading (intra rater reliability).

\section{Results}

For the Arabic Quick-DASH questionnaire, the total mean score was 53.61 \pm 23.49 , ranging from 4.5 and 100 . Floor and ceiling effects show the proportion of individuals who achieve the highest or lowest possible numeric value of a score and are considered present when more than $15 \%$ of the individuals achieve these values. Floor and ceiling effects were used as evaluating content validity. A high floor and ceiling effect could make it difficult to distinguish patients from each other. The floor effect for total score was $1.6 \%$. As well as the ceiling effect was $1.6 \%$. No floor or ceiling effects were noted for total score (Table 1).
Among all the subjects that participated in the study, $62.9 \%$ were female, $37.1 \%$ male, ages from 17 to 65 . The most frequent percentages of injured segments were shoulder $(72.6 \%)$, elbow $(9.7 \%)$, wrist $(6.5 \%)$, hand $(8.1 \%)$, hand and wrist $(3.2 \%)$. Table (2) summarizes participants' demographics.

Reliability of Arabic version of Quick-DASH questionnaire:

The internal consistency of the Arabic version of Q-DASH questionnaire was good with Cronbach's alpha $=0.888$. Furthermore, Table (3) showed Cronbach's alpha if the item was removed with no significant difference from the total scale Cronbach's alpha which confirms a very good internal consistency of the Arabic version of Q-DASH questionnaire (Table 3).

The total value of Quick-DASH questionnaire means \pm SD was $(53.61 \pm 23.49)$ at the first time and (43.81 \pm 22.77$)$ at the second time. The intrarater reliability (between two times) using the ICC showed that there was a high reliability of Arabic version Q-DASH questionnaire (with ICC:0.843 and $p=0.0001$ ) (Table 4).

Validity of Arabic version of Quick-DASH questionnaire:

There were positive strong correlation between the total score and Q1 $(r=0.676, p$-value $=0.0001)$, between the total score and Q2 $(r=0.775, p$-value= $0.0001)$, between the total score and Q3 ( $r=0.747$, $p$-value $=0.0001$ ), between the total score and Q4 $(r=0.691, p$-value $=0.0001)$, between the total score and Q5 $(r=0.687, p$-value $=0.0001)$, between the total score and Q6 ( $r=0.682, p$-value $=0.0001)$, between the total score and Q7 $(r=0.694, p$-value $=$ $0.0001)$, between the total score and Q8 ( $r=0.643$, $p$-value $=0.0001)$, between the total score and Q9 $(r=0.603, p$-value $=0.0001)$, between the total score and Q10 $(r=0.661, p$-value $=0.0001)$, and between the total score and Q11 $(r=0.532, p$-value $=0.0001)$. Based on the significant value obtained by the sig. ( 2 tailed) of $0.0001<0.05$, so it could be concluded that all items were valid (Table 5).

Table (1): Descriptive statistics of Arabic version of Q-DASH.

\begin{tabular}{lccccc}
\hline $\begin{array}{l}\text { Quick-DASH } \\
\text { questionnaire }\end{array}$ & Mean \pm SD & Minimum & Maximum & $\begin{array}{c}\% \text { with } \\
\text { floor effect }\end{array}$ & $\begin{array}{c}\% \text { with } \\
\text { celling effect }\end{array}$ \\
\hline Total score & $53.61 \pm 23.49$ & 4.5 & 100 & 1.6 & 1.6 \\
\hline
\end{tabular}


Table (2): Demographic and clinical characteristics of participants.

\begin{tabular}{|c|c|}
\hline Characteristics & $\mathrm{N}=62$ \\
\hline - Age (years), mean $\pm \mathrm{SD}$ & • $44.65 \pm 13.59$ \\
\hline $\begin{array}{l}\text { • Gender (male/female), } \\
\mathrm{n}(\%)\end{array}$ & • $23(37.1 \%) / 39(62.9 \%)$ \\
\hline $\begin{array}{l}\text { - Injured side } \\
\text { (right/left/both), n (\%) }\end{array}$ & $\begin{array}{l}\cdot 33(53.2 \%) / 23(37.1 \%) / \\
6(9.7 \%)\end{array}$ \\
\hline $\begin{array}{l}\text { - Dominant side (right/left), } \\
\mathrm{n}(\%)\end{array}$ & • $61(98.4 \%) / 1(1.6 \%)$ \\
\hline $\begin{array}{l}\text { - Working status (working/ } \\
\text { student/not working), n (\%) }\end{array}$ & $\begin{array}{l}\text { • } 45(72.6 \%) / 1(1.6 \%) / \\
16(25.8 \%)\end{array}$ \\
\hline \multicolumn{2}{|l|}{ Site of injury, $n(\%):$} \\
\hline • Elbow & - $6 \quad(9.7 \%)$ \\
\hline • Hand & - $5 \quad(8.1 \%)$ \\
\hline - Hand \& wrist & - $2 \quad(3.2 \%)$ \\
\hline - Shoulder & - $45(72.6 \%)$ \\
\hline - Wrist & $\cdot 4 \quad(6.5 \%)$ \\
\hline \multicolumn{2}{|l|}{ Diagnosis, $n(\%)$ : } \\
\hline - Frozen shoulder & • $13(20.9 \%)$ \\
\hline - Supraspinatus tendinitis & - $14(22.5 \%)$ \\
\hline - Impingement syndrome & • $7(11.2 \%)$ \\
\hline • Hill Sachs lesion & - $1(1.6 \%)$ \\
\hline - Adhesive capsulitis & • $4(6.5 \%)$ \\
\hline $\begin{array}{l}\text { - Post traumatic shoulder } \\
\text { tendinitis }\end{array}$ & - $1(1.6 \%)$ \\
\hline - Rotator cuff tendinitis & - $2(3.2 \%)$ \\
\hline - Shoulder OA & • $1(1.6 \%)$ \\
\hline - Shoulder dislocation & - $1(1.6 \%)$ \\
\hline - Shoulder Stiffness & - $1(1.6 \%)$ \\
\hline - Tennis elbow & - $3(4.8 \%)$ \\
\hline - Golfer elbow & - $1(1.6 \%)$ \\
\hline - Olecranon fracture & - $1(1.6 \%)$ \\
\hline - Wrist stiffness & -3 $3(4.8 \%)$ \\
\hline - Carpal tunnel syndrome & - $2(3.2 \%)$ \\
\hline - Hand stiffness & • $4(6.5 \%)$ \\
\hline $\begin{array}{l}\text { - Amputation of index and } \\
\text { middle finger }\end{array}$ & - $1(1.6 \%)$ \\
\hline - Dislocation of left index & - $1(1.6 \%)$ \\
\hline • Nerve injury & - $1(1.6 \%)$ \\
\hline
\end{tabular}

Table (3): Internal consistency of the Arabic version of QuickDASH questionnaire by Cronbach's Alpha.

\begin{tabular}{lcc}
\hline $\begin{array}{l}\text { Item } \\
\text { number }\end{array}$ & $\begin{array}{c}\text { Cronbach's Alpha } \\
\text { if item deleted }\end{array}$ & $\begin{array}{c}\text { Cronbach's Alpha } \\
\text { of scale as total }\end{array}$ \\
\hline 1 & 0.878 & 0.888 \\
2 & 0.872 & \\
3 & 0.871 & \\
4 & 0.879 & \\
5 & 0.881 & \\
6 & 0.876 & \\
7 & 0.876 & \\
8 & 0.879 & \\
9 & 0.882 & \\
10 & 0.877 & \\
11 & 0.887 & \\
\hline
\end{tabular}

Table (4): ICC for test retest intra-rater reliability of Arabic version of Quick-DASH questionnaire.

\begin{tabular}{llll}
\hline Times & Mean \pm SD & ICC & $p$-value \\
\hline First time & $53.61 \pm 23.49$ & 0.843 & $0.0001 \mathrm{~S}$ \\
Second time & $43.81 \pm 22.77$ & & \\
\hline$p<0.05=$ Significant & $p=$ Probability. & &
\end{tabular}

$p<0.05=$ Significant,$\quad p=$ Probability.

Table (5): Pearson correlation coefficients.

\begin{tabular}{lccc}
\hline Item number & $\begin{array}{c}r- \\
\text { value }\end{array}$ & $\begin{array}{c}\text { Correlation } \\
\text { strength }\end{array}$ & $\begin{array}{c}p \text { - } \\
\text { value }\end{array}$ \\
\hline (Total score - Q1) & 0.676 & Strong & $0.0001 \mathrm{~S}$ \\
(Total score - Q2) & 0.775 & Strong & $0.0001^{\mathrm{S}}$ \\
(Total score - Q3) & 0.747 & Strong & $0.0001 \mathrm{~S}$ \\
(Total score - Q4) & 0.691 & Strong & $0.0001^{\mathrm{S}}$ \\
(Total score - Q5) & 0.687 & Strong & $0.0001^{\mathrm{S}}$ \\
(Total score - Q6) & 0.682 & Strong & $0.0001^{\mathrm{S}}$ \\
(Total score - Q7) & 0.694 & Strong & $0.0001^{\mathrm{S}}$ \\
(Total score - Q8) & 0.643 & Strong & $0.0001 \mathrm{~S}$ \\
(Total score - Q9) & 0.603 & Strong & $0.0001^{\mathrm{S}}$ \\
(Total score - Q10) & 0.661 & Strong & $0.0001 \mathrm{~S}$ \\
(Total score - Q11) & 0.632 & Strong & $0.0001 \mathrm{~S}$ \\
\hline$p<0.05$ = Significant, & $p=$ Probability. &
\end{tabular}

\section{Discussion}

The psychometric properties analyzed in this study revealed that the Arabic Quick-DASH showed good validity and reliability, being able to be used as an alternative to the complete DASH.

The shortened version Disabilities of the Arm, Shoulder and Hand questionnaire is advantageous chosen to give because it is easy to use and requires less time to complete [17]. On average, the majority of the studied sample $(89 \%)$ took half the time (3min and 20s) to complete the Brazilian version of Q-DASH compared to the Brazilian version of DASH (7min) with $87 \%$ of the sample confirming the practicality of the reduced version of DASH without missing information. Another study also found an average of $4 \mathrm{~min}$ for DASH and $2 \mathrm{~min}$ for Q-DASH [18].

The shortened version Disabilities of the Arm, Shoulder and Hand questionnaire is a test that is widely used to determine the extent of upper extremity musculoskeletal disorder. It may be used to measure subjective pain and clinical reactions, particularly in relation to the functional performance of the upper extremity, similar to the original version of DASH [19]. The Q-DASH has some drawbacks compared to DASH, such as higher score and lower specificity [18,19]. However, Q$\mathrm{DASH}$ also has values that are quicker and easy to complete the survey than DASH [20]. 
Many studies have analyzed the psychometric properties of patient reported questionnaires in different populations. The Q-DASH has been translated into different languages all over the world including Arabic [21]. All of these versions have been shown to have good reliability and validity, facilitating the wider use of Q-DASH in the upper limb disability assessment. Arabic is the language spoken by the world's Arabic population. To date, however, there is no validation of the Q-DASH in the Arabic language.

Considering the cultural gap and social environment between Arabic and Western countries, the original English version of Q-DASH has been successfully translated and cross-culturally adapted to Arabic rapids, and the aim of this study was to assess the reliability and validity of Arabic QDASH in native Arabic-speaking patients in Egypt who have had UEDs.

The original shortened version Disabilities of the Arm, Shoulder and Hand questionnaire was translated and adapted into Arabic language with patients of different Arabic backgrounds in Kuwait by Alotaibi [21]. This study also supports the validity and reliability of the Quick-DASH with Egyptian patient populations. Thus, it can be officially used in various clinical environments while addressing the utility of its use in such busy clinical environments.

Health-related quality of life questionnaires are very important and valuable for the quantification of patient function and data analysis between studies. Nowadays, with an invigorating strategy through science, technology and education, and more input from science and technology to the world, valid questionnaires are urgently needed to support this vast amount of clinical research. Therefore, valid questionnaires are urgently needed to support this vast amount of clinical research.

The present study was designed to test validity, reliability and reliability of the Arabic version of Q-DASH questionnaire in UEDs in 62 patients in both males and females with various upper extremity disorders. This study was conducted in an outpatient clinic of the Faculty of Physical Therapy, Cairo University.

In our study, Arabic Quick-DASH had good reliability and validity in the assessment of patients with upper limb disabilities. It is of importance to note that the face and content validity of the Arabic version of Q-DASH can also be supported. Hence, since the Arabic version demonstrated adequate face and content validity [21], this also supports the face and content validity of this Q-DASH and ensures its proper use with Arabic speaking populations including the Egyptians. The psychometric properties of the Arabic Q-DASH were very similar to those of the original version and other versions. The Cronbach's alpha was high (0.88) for the Arabic Q-DASH, similarly to the French [10], Turkish [12], Korean [22], Japanese [11], Chinese [14] and Brazilian [13] versions $(0.89,0.84,0.89$, $0.88,0.818$ and 0.88 respectively) and comparable to British [7] and Dutch [22] (0.96 and 0.94). The test-retest reliability for the Arabic Q-DASH was high (ICC:0.843 and $p$-value $=0.0001$ ) which is similar to Japanese [11], Persian [23], Brazilian [13] and Korean [22] $(0.82,0.89,0.81$ and 0.83$)$ and comparable to Turkish [12], French [10] and Chinese [14].

The floor effect for total score was $1.6 \%$. As well as the ceiling effect was $1.6 \%$. The floor or ceiling effects were higher than 0 in previous studies, but both floor and ceiling effects were 0 in this study, which might be due to the following reasons. First, all of the patients included in our study were treated in the outpatient department, so the severity of the symptoms was usually moderate. Second, all of them included patients suffering from chronic diseases. Under these circumstances, their symptoms were persistent, which could be easy to influence the quality of life to a moderate but not to an extreme degree [14].

\section{Conclusion:}

Arabic Q-DASH is a valid and reliable measurement of upper extremity disorders for patients whose primary language was Arabic in Egypt; it can be used to track patient status and outcomes and to promote evidence-based practice. Our results suggested that the Arabic Q-DASH also can be used as an alternative to the full DASH for assessing individuals with upper extremity disorders.

\section{References}

1- MANSKE R.C. and LEHECKA B.J.: Evidence-based medicine/practice in sports physical therapy. Int. J. Sports Phys. Ther., 7 (5): 461-73, 2012.

2- HUDAK P., AMADIO P. and BOMBARDIER C.: Development of an upper extremity health outcome measure: The DASH (Disability of Arm, Shoulder, Hand) The Upper Extremity Collaborative Group (UECG). American Journal of Industrial Medicine, 29 (6): 601-8, 1996.

3- Institute of Medicine: Crossing the Quality Chasm-A New Health System for the $21^{\text {st }}$ Century, $1^{\text {st }}$ Ed. National Academies Press, Washington, 2001.

4- UNSWORTH C.: Measuring the outcome of occupational therapy. Tools and resources. Aust. Occup. Ther. J., 47 (4): 147-58, 2000. 
5- Institute for Work \& Health: The Quick DASH. Information for Users, Glaxo Smith Kline, UK, 2006.

6- DAVIS A.M., BEATON D.E., HUDAK P., AMADIO P., BOMBARDIER C. and COLE D.: Measuring disability of the upper extremity: A rationale supporting the use of a regional outcome measure. J. Hand Ther., 12 (4): 26974, 1999.

7- BEATON D.E., WRIGHT J.G. and KATZ J.N.: Upper extremity Collaborative group. Development of the QuickDASH: Comparison of 3 item-reduction approaches. The Journal of Bone and Joint Surgery (Am), 87 (5): 103846, 2005.

8- GUMMESSON C., WARD M.M. and ATROSHI I.: The shortened disabilities of the arm, shoulder and hand questionnaire (QuickDASH): Validity and reliability based on responses within the full-length DASH. BMC Musculoskeletal Disorders, 7: 44, 2006.

9- GUILLEMIN F.: Cross-cultural adaptation and validation of health status measures. Scand. J. Rheumatol., 24 (2): 61-3, 1995.

10- FAYAD F., LEFEVRE-COLAU M.M., GAUTHERON V., MACE Y., FERMANIAN J., MAYOUX-BENHAMOU A. and POIRAUDEAU S.: Reliability, validity and responsiveness of the French version of the questionnaire Quick Disability of the Arm, Shoulder and Hand in shoulder disorders. Manual Therapy, 14 (2): 206-12, 2009.

11- IMAEDA T., TOH S., WADA T., UCHIYAMA S., OKINAGA S., KUSUNOSE K. and SAWAIZUMI T.: Validation of the Japanese Society for Surgery of the Hand version of the Quick Disability of the Arm, Shoulder, and Hand (QuickDASH-JSSH) questionnaire. Journal of Orthopaedic Science, 11 (3): 248-53, 2006.

12- KOLDAS DOGAN S., AY S., EVCIK D. and BASER O.: Adaptation of Turkish version of the questionnaire Quick Disability of the Arm, Shoulder, and Hand (Quick DASH) in patients with carpal tunnel syndrome. Clin. Rheumatol., 30 (2): 185-91, 2011.

13- DA SILVA N.C., CHAVES T.C., DOS SANTOS J.B., SUGANO R.M.M., BARBOSA R.I., MARCOLINO A.M., MAZZER N. and FONSECA M.C.R.: Reliability, validity and responsiveness of Brazilian version of QuickDASH. Musculoskeletal Science and Practice, 48: 102163, 2020.

14- CAO S., ZHOU R., ZHOU H., CHEN Y., CUI H., LU Z., QIAN Q. and DING Y.: Reliability and validity of simplified Chinese version of quick disabilities of the arm, shoulder, and hand (QuickDASH) questionnaire: Crosscultural adaptation and validation. Clinical Rheumatology, 38 (11): 3281-7, 2019.
15- http://www.dash.iwh.on.ca/assets/images/pdfs/ quickdash_q.pdf.

16- http://www.dash.iwh.on.ca/assets/images/pdfs/dash q.pdf.

17- ORFALE A.G., ARAUJO P.M.P.D., FERRAZ M.B. and NATOUR J.: Translation into Brazilian Portuguese, cultural adaptation and evaluation of the reliability of the Disabilities of the Arm, Shoulder and Hand Questionnaire. Brazilian Journal of Medical and Biological Research, 38 (2): 293-302, 2005.

18- ANGST F., GOLDHAHN J., DRERUP S., FLURY M., SCHWYZER H.K. and SIMMEN B.R.: How sharp is the short QuickDASH? A refined content and validity analysis of the short form of the disabilities of the shoulder, arm and hand questionnaire in the strata of symptoms and function and specific joint conditions. Quality of Life Research, 18 (8): 1043-51, 2009.

19- ANGST F., SCHWYZER H.K., AESCHLIMANN A., SIMMEN B.R. and GOLDHAHN J.: Measures of adult shoulder function: Disabilities of the arm, shoulder, and hand questionnaire (DASH) and its short version (QuickDASH), shoulder pain and disability index (SPADI), American Shoulder and Elbow Surgeons (ASES) Society standardized shoulder assessment form, constant (Murley) score (CS), simple shoulder test (SST), Oxford shoulder score (OSS), shoulder disability questionnaire (SDQ), and Western ontario shoulder instability index (WOSI). Arthritis care \& research, 63 Suppl 11: S174-88, 2011.

20- SU Y.: QuickDASH. Journal of Physiotherapy, 3 (60): 167, 2014.

21- ALOTAIBI N.: Cross-cultural adaptation process and pilot testing of the Arabic version of the Disability of the Arm, Shoulder and Hand (DASH-Arabic). Hand Ther., 15 (4): 80-6, 2010.

22- HONG S.W., GONG H.S., PARK J.W., ROH Y.H. and BAEK G.H.: Validity, reliability and responsiveness of the Korean version of quick disabilities of the arm, shoulder, and hand questionnaire in patients with carpal tunnel syndrome. Journal of Korean Medical Science, 33 (40), 2018.

23- DOGAN S.K., AY S., EVCIK D. and BASER O.: Adaptation of Turkish version of the questionnaire Quick Disability of the Arm, Shoulder, and Hand (Quick DASH) in patients with carpal tunnel syndrome. Clinical Rheumatology, 30 (2): 185-91, 2011.

24- EBRAHIMZADEH M.H., MORADI A., VAHEDI E., KACHOOEI A.R. and BIRJANDINEJAD A.: Validity and reliability of the Persian version of shortened disabilities of the arm, shoulder and hand questionnaire (quickDASH). International Journal of Preventive Medicine, 6 , 2015. 


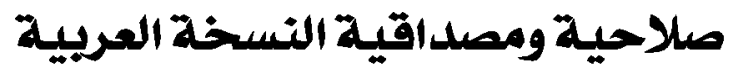 من إستبيان داش المختص لإضطرابات الطرف العلوى الفريلح}

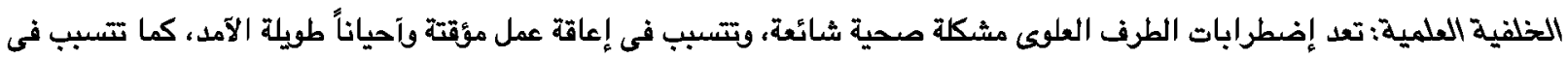

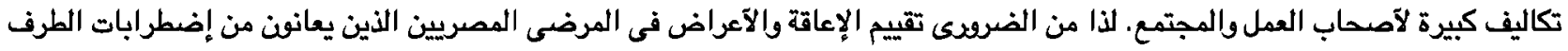
العلوى.

هدف البحث: يهدف هذا البحث إلى تصديد صلاحية ومصداقية النسخة العربية من إستبيان داش المختصر لإضطرابات الطرف العلوى.

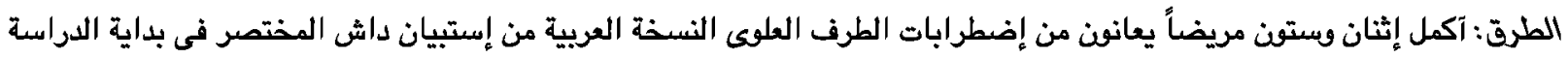

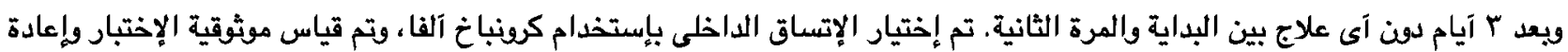
الإختبار بإستخدام معامل إرتباط الطبقة الداخلية.

النتأج: أظهر كرونباخ آلفا من النسخة العربية لإستبيان داش المختصر إرتفاع (كرونباخ آلفا يساوى AMM . .) وكانت موثقتية الإختبار

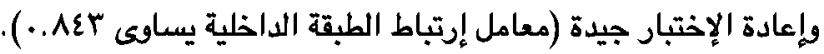

الإستتاج: النسخة العربية من إستبيان داش المختصر هى قياس ذو هلاحية ومصداقية لتقييم مختلف مرضى إضطرابات الطرف العلوى ذوى اللغة الآساسية هى العربية. 